\section{$\underset{\substack{\text { hommes } \\ \text { \& migrations }}}{ }$}

\section{Hommes \& migrations}

Revue française de référence sur les dynamiques

migratoires

1303 | 2013

Diasporas marocaines

\title{
Musique sans frontières
}

Zahia Ziouani, chef d'orchestre

\section{Hélène du Mazaubrun}

\section{(2) OpenEdition \\ 1 Journals}

\section{Édition électronique}

URL : http://journals.openedition.org/hommesmigrations/2580

DOI : $10.4000 /$ hommesmigrations. 2580

ISSN : 2262-3353

\section{Éditeur}

Musée national de l'histoire de l'immigration

\section{Édition imprimée}

Date de publication : 1 juillet 2013

Pagination : 154-157

ISBN : 978-2-919040-23-0

ISSN : $1142-852 X$

\section{Référence électronique}

Hélène du Mazaubrun, " Musique sans frontières », Hommes \& migrations [En ligne], 1303 | 2013, mis en ligne le 23 janvier 2014, consulté le 22 septembre 2020. URL : http://journals.openedition.org/ hommesmigrations/2580; DOI : https://doi.org/10.4000/hommesmigrations.2580 


\title{
COLLECTIONS
}

\section{MUSIQUE SANS FRONTIÈRES ZAHIA ZIOUANI, CHEF D'ORCHESTRE}

\begin{abstract}
HÉLÈNE DU MAZAUBRUN, chargée des collections, responsable de la Galerie des dons, Musée de l'histoire de l'immigration
\end{abstract}

A bdelmadjid Ziouani est né en 1939 à Akfadou, près de Bejaïa en Kabylie. À 18 ans, il part pour Alger travailler dans la restauration. Comme beaucoup de Kabyles qui travaillent partout dans le monde dans ce domaine, le père de Zahia Ziouani décide, par curiosité et opportunité professionnelle, de tenter l'expérience dans les brasseries parisiennes.

Lila Karkar, née en 1947 à Alger, vit dans une ferme sur les hauteurs de la ville, dans le quartier appelé "Bouzarier". Elle suit sa scolarité à l'École française - "par chance", précise Zahia, car tous les enfants ne vont pas à l'école, encore moins les filles. À la fin de ses études, Lila devient secrétaire au ministère de la Justice en Algérie, participant à l'édification d'une administration naissante en Algérie après l'indépendance.

Retournant régulièrement en Algérie pour les vacances, Abdelmadjid rencontre Lila. Ils se marient en 1977, un "mariage d'amour"..., ce qui n'était pas si courant à cette époque. Lila suit son mari à Paris, sans projet défini. Un an plus tard, en 1978, naissent Zahia et sa sœur jumelle, suivies de leur frère à peine deux ans plus tard. Les Ziouani continuent à rendre visite à leur famille algérienne de l'autre côté de la Méditerranée à toutes les vacances. Mais ces allers et retours sont stoppés brutalement : les autorités ont déclaré les voyages "interdits", car trop dangereux. En 1993, la guerre civile et le terrorisme islamiste ensanglantent l'Algérie. C'est le commencement de ce qu'on appellera "la décennie noire" et qui provoque le départ de nombreux Algériens, principalement des étudiants diplômés et des intellectuels (journalistes, écrivains, universitaires, artistes, médecins, ingénieurs), visés par le terrorisme islamiste.

Zahia poursuit son adolescence coupée du pays d'origine de ses parents. Son prénom de consonance arabe l'amène de plus en plus à s'interroger sur sa propre identité et à suivre à distance l'actualité de son pays d'origine. Elle prend conscience de sa double culture parmi les élèves du Conservatoire national supérieur de musique où elle pratique l'alto et la guitare classique. Diplômée en analyse musicale, en orchestration et en musicologie à l'université Paris-IV Sorbonne, Zahia remporte plusieurs prix de conservatoire. En 1996 et 1997, elle suit les cours de direction d'orchestre avec Sergiu Celibidache à Munich, puis elle dirige l'Orchestre symphonique Divertimento, dont elle est aussi la directrice musicale. Elle précise qu'elle doit beaucoup à l'univers musical qui l'a bercée enfant, lorsque sa mère écoutait des vinyles de Mozart et de Beethoven! Son père, autodidacte quant à lui, s'est forgé une culture solide sur les ondes de la radio France Culture. Dès son arrivée à Paris, il s'était rendu à l'Alliance française, afin de perfectionner son français, mais il y fit surtout des rencontres et assista à de nombreux concerts. Au Musée de l'histoire et des cultures de l'immigration, Palais de la Porte Dorée, Zahia fait le don d'une gasba (flûte traditionnelle algérienne), celle que son père lui a offerte quand elle était enfant. 
tel que savoir compter. Je me souviens combien il était exigeant à ce sujet. Enfant, cela me paraissait démesuré, je ne comprenais pas pourquoi cela pouvait être si important. Les vacances en Algérie me paraissaient obligatoires et je ne mesurais pas la richesse que cela représentait, ni combien le retour aux sources est structurant pour se forger une vie dans le présent et dans l'avenir au sein de la société dans laquelle on vit. Je ne l'ai vraiment compris que lorsque le retour en Algérie a été impossible dans les années 1990. À cette époque, je vivais mon adolescence, cette période si cruciale pour se définir soi vis-à-vis des autres, on cherche à ressembler et à se différencier à fois..."

Après ce séjour en Algérie dans les années 2000, Zahia reçoit des propositions professionnelles en tant qu'instrumentiste, puis pour diriger l'Orchestre national symphonique d'Algérie en 2007. Lors de ses premiers

Zahia Ziouani @ MUSÉE NATIONAL de L'HISTOIRE Et DES CULtURES DE L'IMMIGRATION, CNHI

"Mes parents ont la double culture, cétait très évident pour eux. Mais, pour moi qui n'ai jamais vécu en Algérie, ce n'était pas si simple, surtout quand on est jeune, malgré la double nationalité inscrite sur mon passeport. J'ai pris connaissance de cette richesse dans les années 2000, redécouvrant un pays qui, depuis notre dernier voyage, avait pris un tout autre visage, après la décennie noire. La nature était devenue béton, le pays était en construction. Partie d'abord toute seule, c'est à ce moment-là que je suis entrée dans ce pays en pleine évolution."

Zahia a la double nationalité franco-algérienne, mais ce "déclic identitaire" intervient finalement assez tardivement. Pourtant, ses parents ont toujours été soucieux de transmettre cette double culture, celle du pays d'accueil, mais aussi celle du pays d'origine. "Mes parents parlaient arabe et, en Algérie, mon père tenait absolument à ce que nous ayons connaissance des fondamentaux, voyages en Algérie, elle découvre que les grands répertoires européens y sont joués avec des morceaux traditionnels orchestrés à la fin de chaque concert. Cette vision de la musique, “décloisonnéeetsanshiérarchiedesgenres"laséduit. "À chaque concert en Algérie, il y avait toujours beaucoup de monde, car il y a une médiatisation très forte là-bas de la musique classique. Par contre, ici, en France, la médiatisation reste très spécialisée. D'ailleurs, lorsque je vais en Algérie, les gens me reconnaissent dans la rue comme chef d'orchestre! En France, même le plus grand chef d'orchestre n'est pas connu du grand public. J'explique cette différence par le fait que la musique classique est populaire en Algérie." Zahia songe ensuite à mettre en place des programmes franco-algériens et euro-méditerranéens. "Maintenant, c'est un peu un fil conducteur dans mes choix artistiques, de retrouver ces trois axes avec musique classique, populaire et contemporaine."

"À la maison, nous écoutions plutôt de la musique européenne, de la musique classique. Mais, de façon assez naturelle, sans me poser de questions, 
Zahia Ziouani et l'orchestre symphonique Divertimento,

Cité de la Musique, Paris, 2012

(c) Musée national de l'Histolre et des cultures

DE L'IMMIGRATION, CNHI

j'étais attirée par ce qui fait le lien avec l'Algérie et mes origines." Ainsi, adolescente, Zahia avait travaillé sur l'œuvre de Camille Saint-Saëns, Castagnettes de fer. Inspiré par ses voyages en Égypte et en Algérie, ce célèbre compositeur français du XIXe siècle a remplacé pour la première fois les castagnettes de bois par un son métallique aux consonances orientales. Zahia avait pris conscience à ce moment-là que deux cultures peuvent faire naître de grandes œuvres universelles que la musique sait si bien véhiculer, comme une autre de ses œuvres célèbres, le Concerto n 5 dit "L'Égyptien": "L'histoire se passe en Égypte, mais il y a beaucoup de motifs qui sont en fait des mélodies qu'il a reprises presque textuellement d'Algérie... qu'il avait entendues certainement dans des cafés ou dans des fêtes du village. Camille Saint-Saëns a capté cette musique 'orale' qu'il a 'écrite' pour en faire une œuvre magistrale de la musique classique européenne."

Comme un écho à l'œuvre de Saint-Saëns et aux percussions tant aimées de sa mère lors des fêtes en Algérie, Zahia a fait deux autres dons au musée : sa baguette de chef d'orchestre et un instrument qui lui est cher : des karkabous.
Cet instrument percussif est souvent joué dans sa programmation musicale. Parce que les musiciens français de son orchestre ne savaient pas en jouer, elle a fait venir régulièrement des musiciens algériens pour leur enseigner cette pratique.

Mais cette ouverture vers la musique extra-européenne n'est pas seulement dirigée vers l'Algérie ou la Méditerranée. L'œuvre de Saint-Saëns était perçue à son époque comme très contemporaine, ne serait-ce que par cette rencontre musicale de deux cultures aux sonorités si différentes. Ainsi, la démarche de Zahia est clairement celle d'aller puiser chez "l'Autre" ou dans "I'Ailleurs" ce qui peut faire création et participer aux réflexions de la musique contemporaine. Elle invite donc régulièrement des compositeurs contemporains au sein de son orchestre.

En 2007, elle est nommée chef d'orchestre invitée de l'Orchestre national symphonique d'Algérie et reçoit la même année le Premier Prix de musique du président de la République algérienne. Elle se produit dans de nombreux festivals en Russie, Espagne, Allemagne, République tchèque, Pologne, Belgique, et en Algérie. Elle dirige l'école 
de musique et de danse de Stains (Seine-SaintDenis). En intégrant la musique extra-européenne au programme de son orchestre, elle a dû créer des ponts entre les deux cultures. De la diversité de la programmation musicale sont nés un réel échange culturel des savoirs et des pratiques, mais aussi des rencontres humaines. En 2010, par exemple, Zahia est partie avec son orchestre pour un grand concert qui regroupa les deux orchestres, français et algérien.

Au profil atypique, puisqu'elle a grandi en banlieue parisienne, à Pantin, qu'elle est une femme et qu'elle est d'origine algérienne, Zahia Ziouani a malgré tout réussi à devenir chef d'orchestre, ce qui est très différent des parcours habituels en musique classique. Peut-être est-ce pour cette raison que sa démarche pédagogique en direction des jeunes est très importante pour elle. En 2008, elle a été promue chevalier de l'Ordre national du mérite et elle a été invitée à siéger au conseil d'orientation du Musée de l'histoire et des cultures de l'immigration, Palais de la Porte Dorée: "Lorsque le musée a ouvert en 2007, j'ai trouvé cela extrêmement intéressant. Je trouve fondamental le fait qu'un musée tente de comprendre la France à travers son histoire. Et justement, l'immigration fait partie de son histoire

D'autre part, je me suis sentie personnellement concernée, parce que l'immigration fait partie de ma propre histoire."
Zahia Ziouani entourée de ses parents, Lila Karkar

et Abdelmadjid Ziouani (c) Musée national de L'Histoire et des Cultures DE L'IMmigration, CNHI 